This item was submitted to Loughborough's Research Repository by the author.

Items in Figshare are protected by copyright, with all rights reserved, unless otherwise indicated.

\title{
The impact of regional jets on air service at selected US airports and
}

\section{markets}

PLEASE CITE THE PUBLISHED VERSION

https://doi.org/10.1016/j.jtrangeo.2004.04.012

PUBLISHER

(C) Elsevier

VERSION

AM (Accepted Manuscript)

LICENCE

CC BY-NC-ND 4.0

REPOSITORY RECORD

Wong, Yuen-Chong, D.E. Pitfield, and lan M. Humphreys. 2019. "The Impact of Regional Jets on Air Service at Selected US Airports and Markets”. figshare. https://hdl.handle.net/2134/4050. 
This item was submitted to Loughborough's Institutional Repository (https://dspace.lboro.ac.uk/) by the author and is made available under the following Creative Commons Licence conditions.

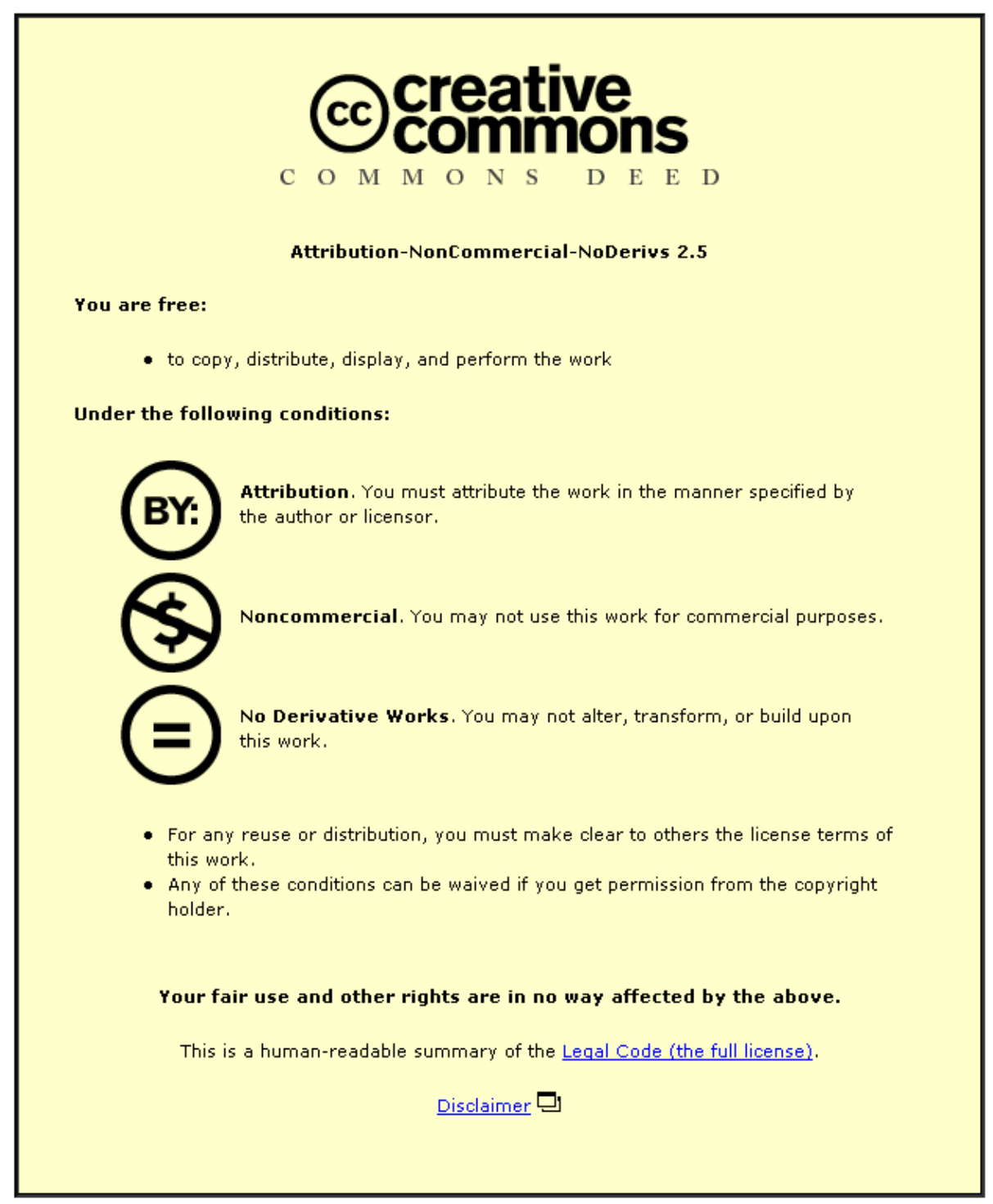

For the full text of this licence, please go to: http://creativecommons.org/licenses/by-nc-nd/2.5/ 


\section{The Impact of Regional Jets on Air Service at Selected US Airports and Markets.}

Derek K.Y. Wong, D.E.Pitfield and I.M.Humphreys

Transport Studies Group

Department of Civil and Building Engineering

Loughborough University

Loughborough

Leicestershire LE11 3TU

UK

E-mail: D.E.Pitfield@lboro.ac.uk

Regional jets, normally defined as jet aircraft introduced since 1993 with less than 100 seats, have been thought to have significant impacts on air services at airports, for example, in improving service frequency, allowing airlines to exploit niche markets and to feed hubs. Previous studies have focused on regional jet deployment strategy and the overall situation and they suggest that deployment was generally to larger cities first and, in addition, to locations east of the Mississippi. It has also been suggested that smaller airports might lose service when regional jets replace turbo-props and that carrier competition would increase, to the benefit of the consumer.

This paper aims to throw more light on these issues from the individual airports' point of view. Data on changes in schedules from the Official Airline Guide (OAG) at a series of case study airports from 1994 to 2002 is used to examine, the impacts on new route development, market dynamics, carrier competition and concentration and deployment status. In particular, the impact on smaller airports is examined.

It is concluded, subject to the usual caveats on sample size, that there is little evidence of a uniform impact on routes or airports. The aggregate picture often described by the industry and government is shown to be a combination of highly dissimilar cases. A spectrum of effects is identified across different types of airports and routes but some of the anticipated trends, such as hub bypassing, are not observed. Some airports reaped significant benefits in terms of improved frequency and services to new destinations, whilst others gained little. 


\section{Introduction}

There is no universally accepted definition of a Regional Jet (hereafter, RJ) in the airline industry or in U.S. laws or regulation (General Accounting Office, 2001, DOT, 1998). Whilst it is usually acknowledged that Airbus and Boeing aircraft are not considered RJs (MITRE, 2000, Goold, 2001), the broadest definition considers all jet aircraft under 100 seats as RJs (MITRE, 2000¹). This covers older aircraft such as the Fokker F.28 and British Aerospace 146 (Bernstein \& Abbey, 1997). However, the notional 'revolutionary' impact on the industry was brought on by the introduction of more modern RJs, notably Bombardier's Canadair Regional Jet. A more common definition in the industry is therefore 'jet aircraft put in service since 1993 designed to seat 100 or fewer passengers' and it is this that is used here. The GAO report adopts a definition similar to this and Appendix A provides a list of RJ models considered in this paper.

The impact of the RJs on domestic air transport in the United States (Delta Airlines, 2002, RAA, 2001, RAA, 2002, Graham, 1997, DOT, 1998, Croft, 2002) is commonly referred to as a revolution. RJs have become a significant component of American air transport (Razzhivina, 2001) and airlines have adopted new strategies in order to exploit the unique characteristics of the aircraft whilst new patterns of air service have emerged (Vowles, 1999, Bernstein \& Abbey, 1997). This growth reflects passenger preference (Dresner, 2002, Pagiola, 2002) and operating characteristics and economics (Jaworoski, 2000, DOT, 1998, GAO, 2001).

When the first RJ was delivered by Bombardier in 1992, the industry was pessimistic about its future (Fiorino, 2002). However, in 1993, Comair introduced the first RJ service in the U.S. market (Sobie, 2002) and by 1996, there were under 100 RJs deployed in the country (RASI, 2003, Higgins, 2001). By 1997 the industry as a whole began to adopt RJs (RAA, 2002) and 861 were in operation in America in 2002 (Delta Airlines, 2002). The GAO (2001) reported that at January 2001, 1,255 RJs had been ordered and 1,010 were on option and the Federal Aviation Administration (FAA) estimated 2,190 RJs by 2012 (Higgins, 2001) whereas Arnoult (2002a) predicts the figure to be 6,261 by 2020.

\footnotetext{
${ }^{1}$ MITRE is a not-for-profit national resource that works in the public interest to provide systems engineering, research and development, and information technology support to the US government. It operates federally funded research and development centres for the Department of Defence, the Federal Aviation Administration, and the Internal Revenue Services. (MITRE, 2002)
} 
The RJ market has been identified as the fastest growing segment of the U.S. airline industry (Delta Airlines, 2002, RAA, 2002) and although different sources report varying statistics on RJ deployment, often with discrepancies, nevertheless, all sources indicate rapid growth in the U.S. RJ fleet as shown in Figure 1.

\section{Figure 1: RJ fleet growth $1992-2001$}

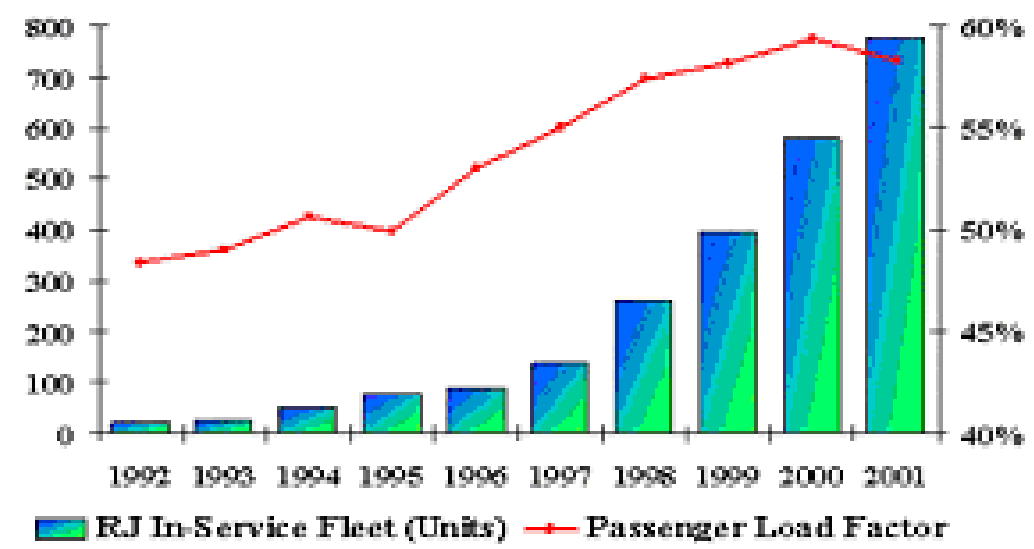

Source: Regional Air Service Initiative (RASI, 2003)

Growth in the RJ market by far outstrips that of the rest of the industry. Between May 1997 and October 2000, the number of monthly RJ departures rose by 735 percent. This contrasts with the 9 percent for mainline jets (i.e. jets bigger than RJs, hereafter MJs) (GAO, 2001). The MITRE Corporation estimated a 31 percent (compounded yearly) increase in RJ traffic between February 1998 and December 2003. This compares with the 3 percent predicted for MJs by the FAA (GAO, 2001).

The most comprehensive prior study of RJ deployment is the General Accounting Office report (GAO, 2001). The report investigated the status of RJ deployment in the U.S. and how air service has subsequently evolved in broad terms from 1997 to 2001. Airline deployment strategy was also examined as well as RJs' impact on air traffic and congestion ${ }^{2}$. It shows that as of October 2000, major airlines provided regional jet service to 157 U.S. cities, only 13 (eight percent) of which were small cities with populations under 100,000. Larger cities (those with populations over 250,000)_represented 74 percent (115) of the total U.S. cities receiving regional jet service. Most of this regional jet service has radiated from the carriers' hubs to spoke cities that the carriers were already serving with either

\footnotetext{
${ }^{2}$ In addition, Dresner et al. (2002) addressed the subject of how RJs are utilized by airlines and the aircraft's impact on passenger demand.
} 
turboprops or mainline jets. Of the markets in which air carriers began regional jet service since May 1997, 41 percent were new markets in which the regional jet carrier had not previously flown. Air carriers used regional jets in these new markets to expand their networks, although another carrier may already have been providing service in some of these locations. The airlines have tended to use their regional jets to serve more distant cities (between 350 and 1,200 miles) that previously were beyond their turboprops' practical operating range or had too few passengers to be profitably served by mainline jets. Because those more distant cities may have been served only by other airlines, regional jets have provided passengers in those cities with additional choices among airline networks. Service to small communities— to which the airlines now mostly operate turboprop aircraft—continues to be an important concern, because of the uncertainty about whether those markets may generate enough passenger traffic and revenue to be financially viable to sustain RJ operations.

These findings are based on national figures and individual cases may diverge significantly from the national average. Consequently this paper investigates how particular airports' experience with RJs may differ by using a case study approach. It examines the impact of RJs on air service from the airports' viewpoint. This includes examining aspects of air service such as the number and nature of new routes (which confers benefits on consumers), capacity and frequency within particular markets, as well as carrier competition. The airports examined are New York La Guardia, Cincinatti/ Northern Kentucky International Airport, Phoenix Sky Harbor International, Savannah/ Hilton Head International and Lincoln Municipal Airport.

\section{Methodology}

The five case study airports were chosen for their varied and contrasting characteristics, such that the impact of RJs on different airports could be compared. They were not chosen to represent the heaviest RJ use, nor to be representative; they were selected to illustrate a variety of perspectives, as is shown below. Their locations in the United States are indicated in Figure 2. 


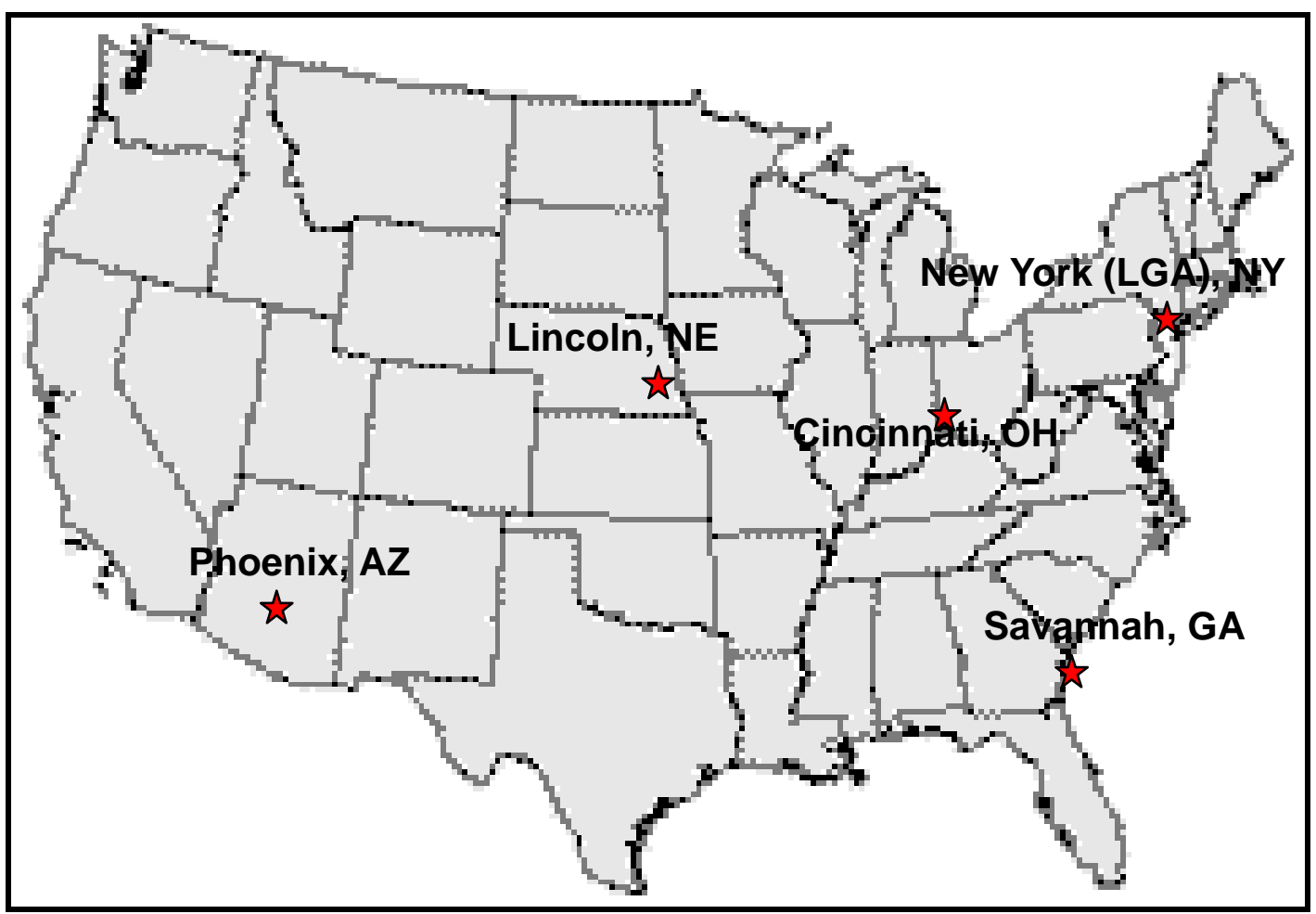

Cincinnati/Northern Kentucky International Airport (CVG) had 17.3 million passengers in 2001 (ACI, 2002), and is considered as a large hub by the FAA. Comair, which pioneered the RJ in the U.S., was based in Cincinnati. The airline has since been incorporated into Delta airlines, the biggest operator of RJs in the world (GAO, 2001).

Delta heavily dominates the airport (Belobaba \& Van Acker 1994) and has built up the biggest American RJ base there. RJ traffic feeds provide 14 points of Delta's load factor at the airport. With 350 daily RJ and 160 MJ departures, CVG is ‘by far the most RJ-dependent hub’ (Sobie, 2002).

Cincinnati is favourably situated 'in the middle of the country', within RJ range of numerous 'little big cities' that are profitable markets for RJ operations (FAA, 1997). The recent growth in traffic at the airport has allowed it to compete with other hubs nearby (FAA, 1997). RASI (2003) describes CVG as a 'benchmark' for RJ operations. The sheer scale of RJ activity and Delta's RJ hub strategy at CVG warrant a closer examination of the airport.

New York LaGuardia Airport (LGA) handled 21.9 million passengers in 2001 (ACI, 2002). LaGuardia airport is a one of the three airports serving the New York City area and the FAA designates it as a 
large hub. However, LGA is not a 'hub' in the sense of 'hub and spoke' or 'fortress hub'. LGA's origin and destination traffic is relatively high and no particular carrier dominates the airport, resulting in a high level of inter-airline competition. Some carriers have used RJs as a competitive tool to enter the LGA market (Sobie, 2002).

LGA is also one of the most congested airports in the U.S. and slot restrictions limit access to the airport (Morrison \& Winston, 1995). The W. H. Ford Aviation Investment Reform Act for the $21^{\text {st }}$ Century (AIR-21), however, grants exemptions to carriers that replace turboprops (hereafter, TBPs) with RJs for small community services. By September 2000, airlines have added nearly 200 new scheduled RJ flights under the rule (RASI, 2003).

Lincoln Municipal Airport (LNK) handled 470,000 passengers in 2001 (ACI, 2002) and it is a non-hub by FAA definitions. It is a small community at risk of losing air service as RJs replace TBPs. LNK’s location in the mid-west also makes it especially unattractive for RJs operations and the region has previously been identified as a 'high risk zone' for air service loss (Vowles, 1999). LNK was examined to see if concerns over small community air service have materialised.

Phoenix Sky Harbor International Airport (PHX) is the largest of the sample airports in terms of passenger traffic. It handled 35.4 million passengers in 2001, ranking $6^{\text {th }}$ among U.S. airports and $11^{\text {th }}$ worldwide (ACI, 2002). The primary reason for selecting PHX is its geographical location. The GAO pointed to PHX as an example of RJ opportunities being limited by an airport's location (GAO, 2001). Phoenix’s and Arizona's relative isolation means fewer large cities are located near the airport. Comparing PHX with airports from other parts of the U.S. demonstrates how the impact of RJs could differ according to an airport’s geographical location.

Savannah/Hilton Head International Airport (SAV) had 1.7 million passengers in 2001 (ACI, 2002) and the FAA designates SAV as a small hub. The city of Savannah has only 300,000 residents but it is near the tourist area of Hilton Head Island. Savannah is often used as a showcase of how RJs could help small/medium-sized airports grow. Since mid-1997, virtually every new scheduled flight at the airport was flown by RJs (RASI, 2003). The growth in passenger numbers attributable to RJs is 
'dramatic'. Examining SAV gives an idea of what RJs mean to medium/small airports as spokes to hubs.

For each of these airports, Official Airline Guide (OAG) flight data was the source of information used for analysis. OAG data included information on scheduled flight destinations, times, operating carrier, equipment type and route stage length. Comparing and observing changes in these elements of schedule data formed the basis of the analysis. OAG data for the years 1994 (Jun), 1996 (Jun), 1998 (Jul), 2000 (Jul) and 2002 (Jun) were analysed to give a reasonable picture of how the situation has evolved over the past decade since RJs were first deployed in the U.S. This every second year sample collection method was also employed in other studies, such as Belobaba \& Van Acker (1994) who dealt with airline market concentration. Analysing only summer months minimised the seasonality effect in air service. Only non-stop, domestic, routes with at least one daily flight were analysed. Connecting flights are not relevant to the research topic and including them would result in double counting. Most RJ flights in the U.S. are domestic and many additional factors influence equipment deployment strategies for international flights. Only routes with at least one daily flight were considered because they are most indicative and representative of an airport's air service level. Attention was also paid to code-shared flights such that they are not counted twice. The integrity of OAG data was assumed.

It is clearly the case that a study based on five case studies does not enable wide ranging statistically significant conclusions to be reached, but, nevertheless, the case study approach does allow significant situations and circumstances to be illustrated. It may, in turn, suggest the need for a more comprehensive study. 


\section{Results: Deployment at the Selected Airports}

The first section of the results examines the number and growth of RJ routes; the share of routes served by RJs and the type of destination served.

\subsection{The number and growth of RJ routes}

Figure 3 summarises the number of RJ routes at the sample airports for the sample years. It includes all routes either exclusively or partially served by a RJ.

Figure 3: Number of routes with RJ service

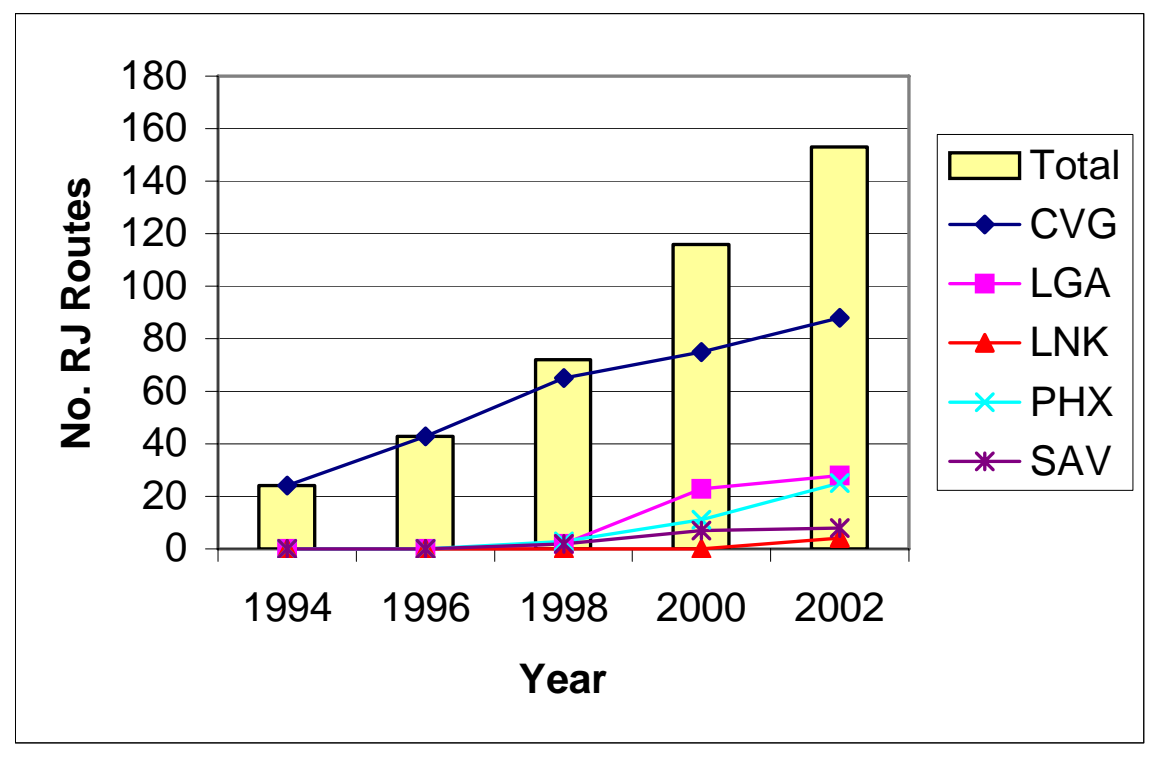

Source: $O A G$

The total number of markets with RJ service grew from 24 in 1994 to 153 in 2002. This rapid growth agrees with all previous studies, which also indicated that the use of RJs has expanded dramatically in the past decade. What those studies did not reveal, however, is the difference in timing and volume of $\mathrm{RJ}$ deployment between airports.

This analysis shows that while Cincinnati had RJ services as early as 1994, RJs only began serving other sample airports after 1996. RJs did not enter the Lincoln market until the period between 2000 and 2002. CVG's early start may be explained by the presence of Comair, which pioneered the RJ movement. At the remaining airports, RJ service remained insignificant even by 1998 . 
CVG represented all RJ services between 1994 and 1996 at the sample airports. Even in 2002, the airport was still responsible for over half of all RJ routes being flown among this sample. It is evident that airports with greater annual passenger numbers (e.g. PHX and LGA) did not necessarily attract more RJs, while Comair and Delta's strategy probably contributed to the high level of RJ deployment at CVG. The rate of growth of RJ routes among the airports also varied greatly. If routes that only use RJs are examined a similar overall growth trend can be observed.

\subsection{The proportion of RJ routes}

Having shown the rapid increase in the number of routes on which RJs were deployed, the share of routes that were served in total by RJs was calculated for each airport.

Figure 4: Proportion of routes with RJs

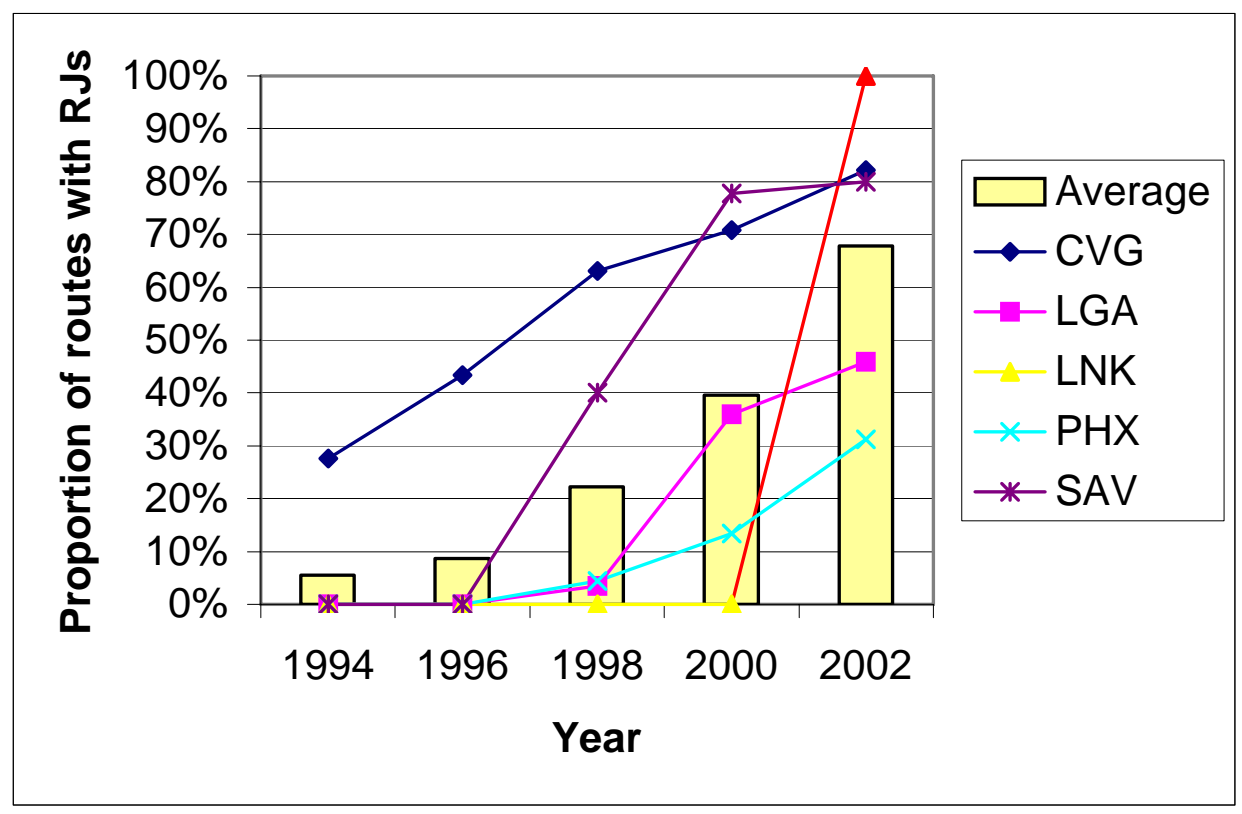

Source: $O A G$

Figure 4 shows the increase in the proportion of RJ markets and this reflects the growth in RJ deployment. From an average of below 10 percent in 1994, the figure reached 67.88 percent by 2002. RJs have therefore 'taken over' more routes or opened new markets for the airports. Lincoln's situation is most striking of all. Without a single RJ service in 2000, every route by 2002 involved RJs. Although the base number is small (4), the finding is interesting nevertheless. The impact of RJs could be much more dramatic for small airports than for larger ones. 
The experience of individual airports is instructive, for example, Savannah had a much higher proportion of exclusively RJ routes since the airport began having RJ service in 1998 . So although CVG may be perceived as more RJ-intensive in terms of the proportion of routes with RJ service, SAV is in fact more RJ-reliant. 70 percent of SAV's routes depended exclusively on RJs by 2002. This observation adds to the established understanding that large and medium-sized cities have received the vast majority of RJ service (GAO, 2001).

The results also shed light on industry fears that small communities would suffer as carriers turn to alljet fleets. While the fact that all of LNK's routes involved RJs may be a sign that RJs have pushed turboprops out, three-quarters of RJs routes were served by other aircraft along with RJs. This suggests that RJs could be deployed together with other aircraft types within a particular market rather than losing service.

\subsection{The nature of RJ routes}

Other than the quantity of RJ routes, it is also important to understand the nature of these routes. The size of all RJ route destinations was identified using FAA's definition of large, medium, small and nonhubs. The analysis consistently applied FAA’s categorisation according to 2001 traffic figures.

Figure 5: Size of RJ destinations (average percent since introduction of RJs at the airport between 1994-2002)

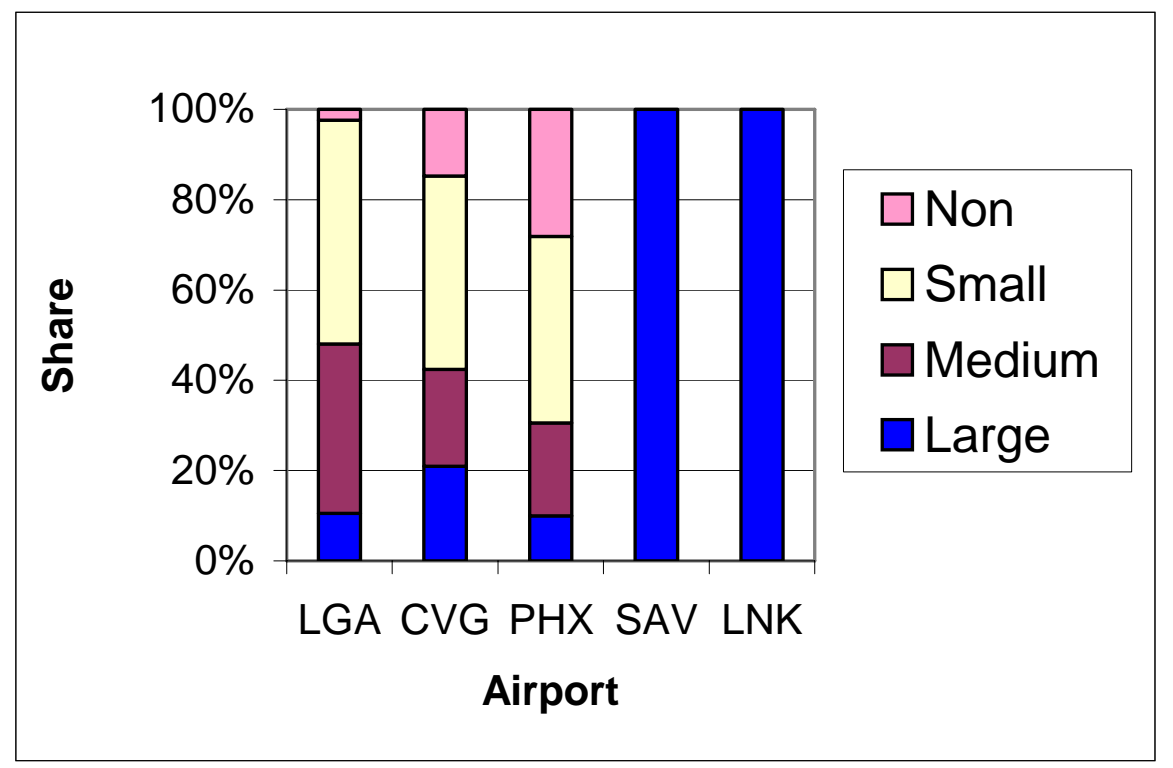

Source: $O A G$ 
Figure 5 shows that the types of routes on which RJs were deployed varied greatly between airports. All RJ routes from the smaller airports had large hubs as destinations. Although this may be related to the nature of air service at the airport itself, it also suggests that carriers have not rushed to do hub bypassing with RJs. Since RJs continued to operate through hubs and given the rise in RJ numbers, the industry is rightly concerned with RJs' impact on airport congestion.

At the large airports, RJs were clearly used on a more diverse set of routes, even though medium/small airports represented the bulk of RJ destinations. The latter is consistent with the airlines' strategy of using RJs to add new spokes to their hubs. CVG had a large share of hub destinations whereas PHX's relatively high proportion of RJ routes to non-hub destinations may be related to its geographical location, with few large cities in the region suitable for RJ operation. It is also interesting to note that RJs were also used to serve large hub-large hub routes at congested LGA. The airport is capacity constrained and yet small RJs are operated on high volume routes to maintain frequency. The data was disaggregated to reveal how the situation evolved from one period to another and this reveals a gradual diversification of RJ routes at the larger airports. In 1998, all RJ routes at PHX had small hubs as destinations. By 2002, all types of destinations were represented. Although less explicit, similar trends are found in LGA and even CVG. RJ deployment tended to initially focus on routes to small/medium-sized airports before extending to large and non-hubs.

\section{Impact Of RJs on Air Service at the Selected Airports}

\subsection{The number of new routes}

In this section, RJs impact on airports in terms of providing services to new markets is examined. For each sample year, new routes were identified from the list of all routes and the same was done for the list of RJ routes. A 'new route' was defined as a route operated in the year concerned but that was not (regardless of aircraft used) in the previous sample year. As a result, a 'new route' may be a route never operated before or an upgrade in service to the 'daily' level. Alternatively, a new route could also be one that was previously served indirectly but has become a non-stop service. The New York LaGuardia - Birmingham, Alabama route, which included a stopover before 2000, is an example. Reinstated routes, i.e. routes that were previously terminated but served again, were also considered as 
'new'. This allows the compilation of figures for each airport for each surveyed year. Figure 6 shows the total number of new markets served $1996-2002^{3}$.

Figure 6: Total number of new markets served exclusively by RJs 1996 - 2002

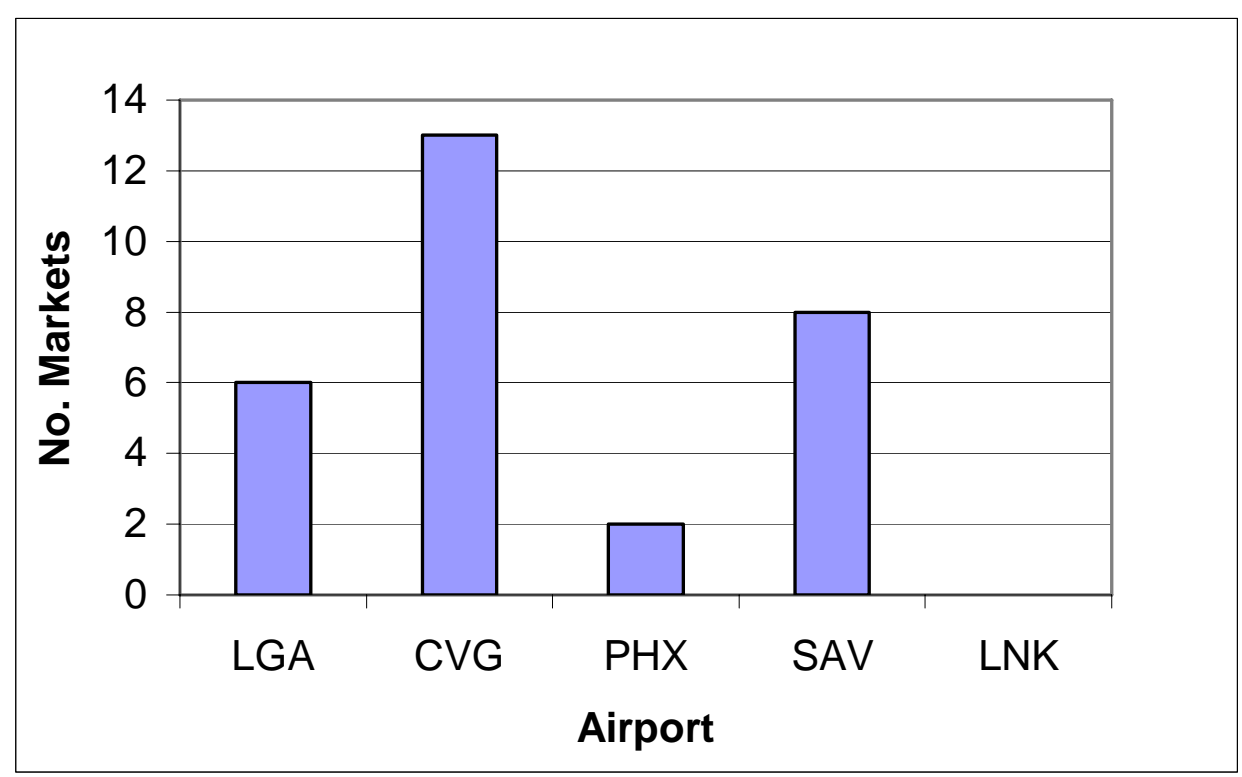

Source: $O A G$

The unevenness of the results is clearly shown. RJs have facilitated the highest number of new markets at CVG, followed by SAV and LGA. PHX only received two all-RJ new routes and LNK none. This variation in whether RJs contributed to new market development depends on a variety of factors, from special legislation (e.g. AIR-21 at LGA) ${ }^{4}$ to airport location and size (e.g. LNK).

Most airports received their highest number of new markets served exclusively by RJs between 1998 and 2000. This reflects the general pace of new market development regardless of aircraft used. CVG received all-RJ new routes as early as 1996 and SAV 1998 whereas LGA and PHX did not until 2000. The cumulative percentage growth in total market number brought about by all-RJ new routes is examined in Figure 7.

31996 is the first year for which new destinations are identified as the data collection began with 1994 data and this was treated as the base year.

${ }^{4}$ AIR-21 gives RJ services special privileges in slot allocation 
Figure 7: Cumulative percent growth in total markets attributable to RJs 1996 - 2002

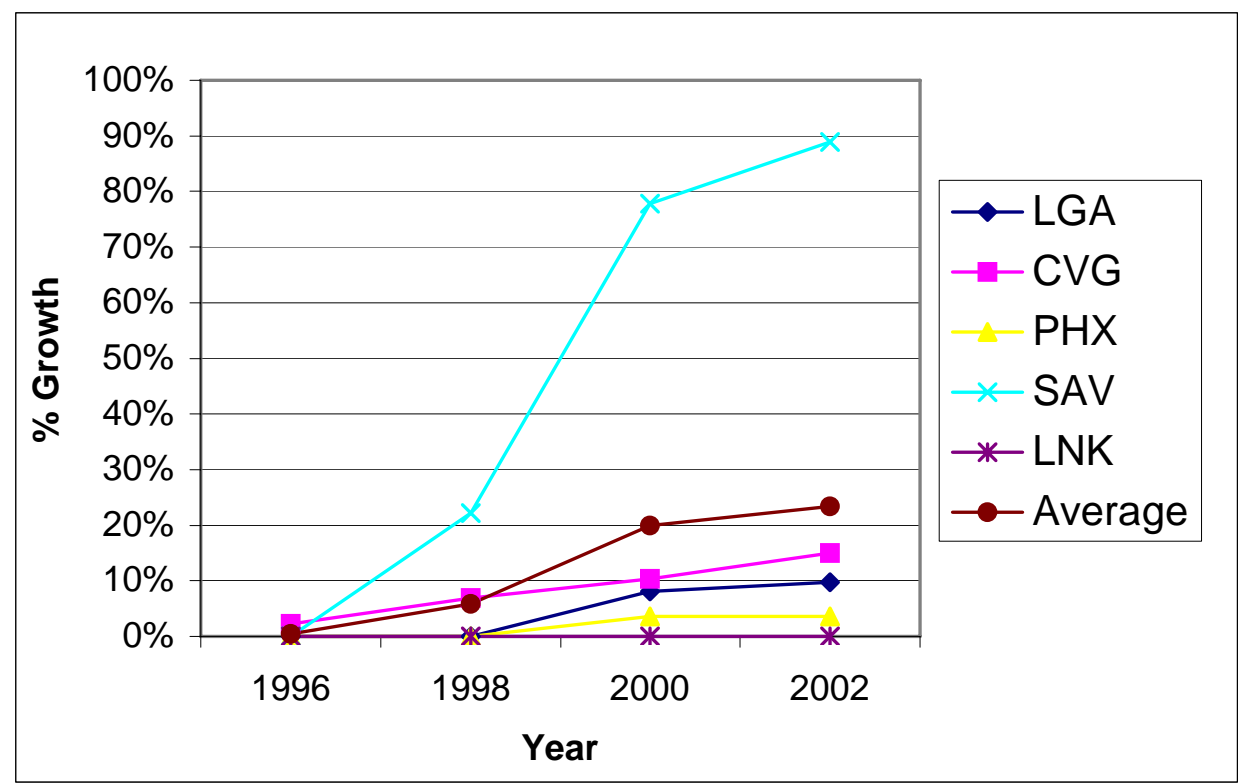

Source: $O A G$

It can be seen that although CVG received the highest absolute number of new markets, it was SAV that reaped, by far, the highest percentage increase in the number of routes flown. On average, airports saw a 23 percent increase in total market number thanks to all-RJ routes. One of the key findings, therefore, is that average statistics on RJs may be extremely misleading as in this case, SAV's 89 percent contrasts with LNK’s 0 percent.

Figure 8: Share of new markets served exclusively by RJs (average 1996 - 2002)

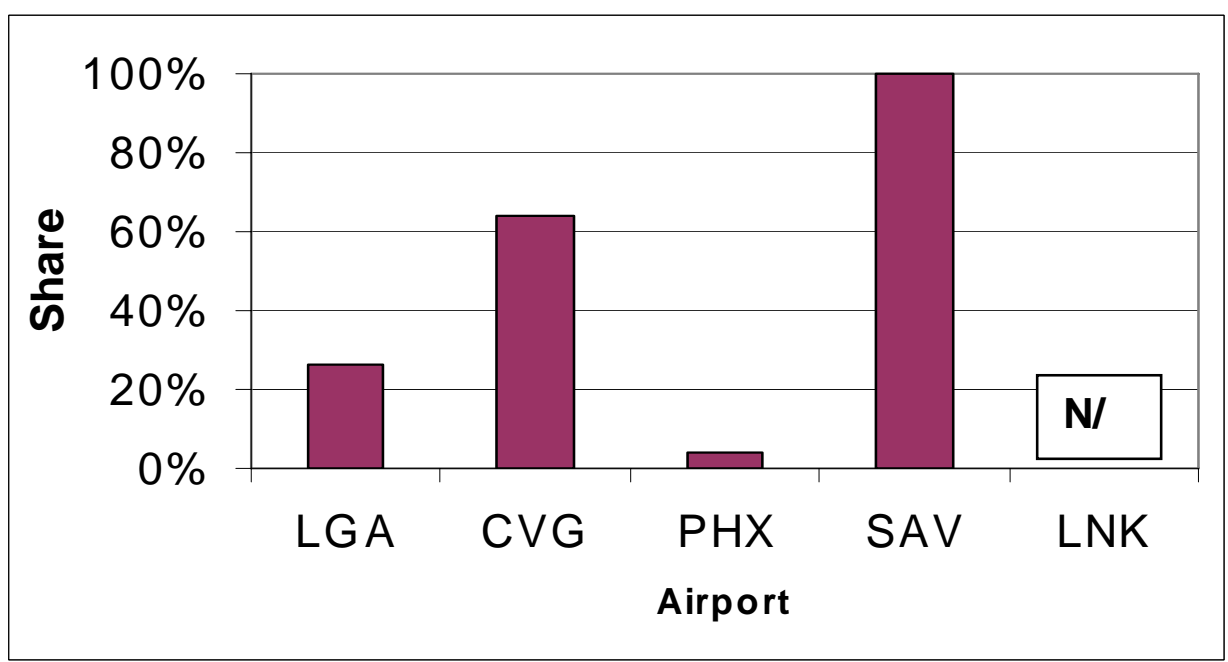

Source: $O A G$ 
In addition, some airports are more reliant on RJs for launching new routes. Figure 8 shows that all new routes at SAV were exclusively RJ markets while the figure was below 5 percent for PHX. RJs, then, played an important part in the growth of destination choice at SAV. Other aircraft have not been used to provide any new routes, not even along with RJs. One could expect that without RJs, the range of destinations available from SAV would be much more restricted.

More than 60 percent of markets in which RJs were deployed at SAV were all-RJ new markets. Despite also establishing a significant number of new routes at CVG, the analysis revealed that developing new markets was not RJs' main role there. The proportion was also very low for other airports. So while the industry touted the RJ as the ideal seed vehicle for developing new markets only a small proportion of RJs were in fact used for that purpose. Except in SAV, the vast majority of RJs were deployed for other purposes, such as supplementing MJs in existing markets or replacing TBPs and this is in contrast to the average of 41 percent reported deployed in new markets in GAO (2001).

4.2 The nature of new routes - destination airport size

Using FAA’s hub definitions and 2001 traffic figures again, the size of every new destination served exclusively by RJs were categorised and this is shown in Figure 9.

Figure 9: Airport size of new destinations served exclusively by RJs (average 1996 - 2002)

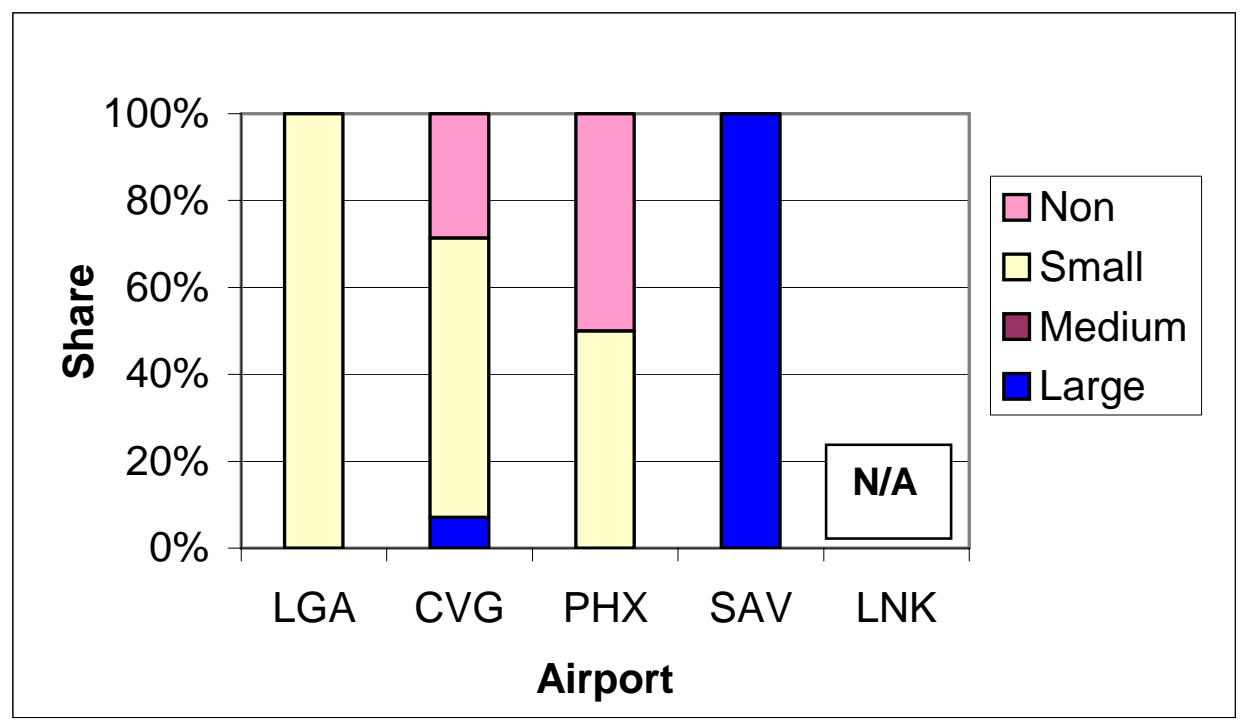

Source: $O A G$ 
New routes from the larger airports principally had small hubs and non-hubs as destinations. This contrasts with the overall deployment trend of RJs, which features small and medium hubs as major recipients of RJ services. This suggests that the new markets developed by RJs were different in nature compared to existing RJ destinations. LGA is a good example as all new markets being served exclusively by RJs were small hubs. This suggests that RJs were used on 'thin' routes and this is probably related to the AIR-21 initiative, which is designed to favour services to small communities.

Small airports' situation contrasted with that of their larger counterparts. All existing RJ routes from SAV and LNK were to large hubs and new destinations attributable to RJs were no different. So even in the development of new markets there is no evidence of hub bypassing, although it was not to be expected for such smaller/non-hub cities.

Having reviewed the size of new destinations linked up by RJs to the sample airports, it is possible to gauge how RJs have improved small airports' access to large hubs. This is important because small airports rely on connections through large hubs to access other parts of the air transport network. Improved access to large hubs would mean significant benefits to travel options.

The number of large hub destinations in 1994 and 2002 were compared for LNK and SAV. Since RJs did not contribute to any new routes at LNK, RJs have had no impact on LNK's access to large hubs. On the other hand, SAV had a total of ten large hub destinations in 2002 compared to six in 1994. While one large hub route (Tampa) was dropped between 1994 and 1996, four were added using RJs exclusively and another with partial RJ service. RJs have therefore vastly improved the choice of large hub destinations available at SAV. From LNK and SAV's case studies, it appears that the impact of RJs has been more positive at small hubs than non-hubs.

\subsection{The nature of new routes - stage length}

The analysis of stage lengths enables the determination of whether RJs have been used to exploit 'long thin' routes. In addition, if small airports' new large hub destinations are further away than the large hubs previously served, this suggests that RJs have brought about network overlap and increased carrier competition. 
New routes, served exclusively by RJs, differed from existing markets and other new routes in terms of stage length. While new routes attributable to RJs were similar in length to existing ones at CVG, they were longer at SAV and shorter at PHX. RJs, then, could facilitate a diversity of new routes, having longer, shorter or similar stage lengths than existing ones and varying from airport to airport. They have often filled the gap between the operating characteristics of TBPs and MJs, for example, making thin medium range routes viable at PHX, whereas RJs simply replaced TBPs on existing routes at LNK. The range capabilities of RJs are, however, not always exploited.

\subsection{Summary: Impact of RJs on Air Service}

RJs' impact on new routes can be summarised. For CVG, probably due its strategic location and Delta’s strategy, RJs facilitated many new routes to airports of various sizes in its surrounding region. For LGA, RJs and special legislation made new routes to small communities possible. The ability of RJs to serve long-thin routes was also displayed. On the other hand, RJs did not benefit LNK at all in terms of new destinations. At PHX, RJs facilitated routes that were beyond TBP's range and probably too 'thin' for MJ service. However, the number of new services attributable to RJs there is low. SAV appears to have benefited most from the deployment of RJs. Its portfolio of destinations expanded substantially in number and in type. Although no trace of new hub bypassing routes could be found, new routes attributable to RJs were clearly longer than existing ones, suggesting network overlap. Its access to large hubs vastly improved too. RJs' impact regarding new routes clearly varied between the sample airports - quantitatively and qualitatively.

A gradual diversification of RJ routes could be observed at the larger airports. In 1998, all RJ routes at PHX had small hubs as destinations. By 2002, all types of destinations were represented. Although less explicit, similar trends are found in LGA and even CVG. RJ deployment tended to initially focus on routes to small/medium-sized airports before extending to large and non-hubs.

\section{The Impact of RJs at Small Airports}

In this section the impact on smaller airports is the focus. This enables a deeper insight to be gained on how RJs have affected small airports, to which RJs offered much hope of air service improvement. 
How RJs have altered the overall condition of air service at LNK and SAV is discussed. The paper also sheds light on industry fears that the rise of RJs and all-jet fleets would threaten small community air service by pushing TBPs out of the market.

\subsection{Route by Route analysis}

Every route that has been operated from SAV and LNK during any of the sample years was analysed. For each route, the number of daily flights and the equipment used were first examined. Aircraft used were grouped into three categories: turboprops, regional jets and mainline jets. Appendix B provides a list of aircraft observed in the study.

All routes with RJ service were also classified into groups similar to the GAO's RJ deployment categories. The routes’ capacity and service frequency were then calculated. Capacity was computed by considering the typical seat capacity of the aircraft deployed on each frequency. Appendix B also shows the typical seating capacity of the aircraft observed.

The number of airlines that operated the route and the subsequent shares of capacity and frequency were also worked out. Two techniques were used to measure carrier competition, as no single measure can describe market concentration in full (Belobaba \& Van Acker, 1994). The first is a count of total effective competitors in the market. This is used instead of a pure count of competitors because airlines with too small a share of the market would not be able to influence the level of competition. For air transport markets, it is generally assumed that effective competitors have at least 5 percent of the market (Belobaba \& Van Acker, 1994). The second measure used is the Hirschman-Herfindahl Index (HHI). The HHI reflects the assumption that larger airlines in a market have disproportionate market power by squaring each carrier's market share value. HHI values therefore range between 0 and 10,000. As a rule of thumb, HHI values above 1,800 indicate high levels of concentration (Belobaba \& Van Acker, 1994). An inverse relationship between the two measures was expected.

Since schedule changes often occurred within a month and especially during the first two weeks, all analysis was conducted using flight data of the week from the $20^{\text {th }}$ to the $26^{\text {th }}$. Code shared flights were counted as one and Trans World Airlines was considered as American Airlines throughout the 
analysis due to their later merger. The two carriers did not previously compete directly on routes used for this analysis.

Table 1 and Table 2 list every route that has been operated at SAV and LNK during the period of study.

The period of operation, year by which RJs have been introduced and respective RJ deployment category are also shown.

Table 1 Routes from SAV (Savannah Int'l Airport, Georgia)

\begin{tabular}{|l|l|l|l|l|}
\hline & Route & Years Operated & $\begin{array}{l}\text { Year of RJ } \\
\text { Introduction }\end{array}$ & $\begin{array}{l}\text { Deployment } \\
\text { Category }\end{array}$ \\
\hline 1 & SAV-Cincinnati & 2000,2002 & 2000 & New route \\
\hline 2 & SAV-Dallas/Fort Worth & $1994,2000,2002$ & 2000 & Reinstated route \\
\hline 3 & SAV-Detroit Metropolitan & 2002 & 2002 & New route \\
\hline 4 & SAV-New York Newark & $1998,2000,2002$ & 1998 & New route \\
\hline 5 & SAV- Washington Dulles & $1998,2000,2002$ & 1998 & New route \\
\hline 6 & SAV-Houston Bush Intercontinental & 2000,2002 & 2000 & New route \\
\hline 7 & SAV-New York LaGuardia & $1994,2000,2002$ & 2000 & Reinstated route \\
\hline 8 & SAV-Chicago O'Hare & $1994,2000,2002$ & 2000 & Reinstated route \\
\hline 9 & SAV-Atlanta Hartsfield & $1994,1996,1998,2000,2002$ & N/A & No RJ service \\
\hline 10 & SAV-Charleston Int'l & 1994,1996 & N/A & No RJ service \\
\hline 11 & SAV-Charlotte Douglas & $1994,1996,1998,2000,2002$ & N/A & No RJ service \\
\hline 12 & SAV-Jacksonville Int'l & 1994 & N/A & No RJ service \\
\hline 13 & SAV-New York J.F.Kennedy & 1996 & N/A & No RJ service \\
\hline 14 & SAV-Raleigh-Durham & $1994,1996,1998$ & N/A & No RJ service \\
\hline 15 & SAV-Tampa Int'l & 1994 & N/A & No RJ service \\
\hline
\end{tabular}
Source: $O A G$

Table 2: Routes from LNK (Lincoln Municipal Airport, Nebraska)

\begin{tabular}{|l|l|l|l|l|}
\hline & Route & Years Operated & $\begin{array}{l}\text { Year of RJ } \\
\text { Introduction }\end{array}$ & RJ Deployment Category \\
\hline 1 & LNK-Denver Int'l & $1994,1996,1998,2000,2002$ & 2002 & RJs \& TBPs replacing MJs \\
\hline 2 & LNK-Minneapolis/St. Paul & $1994,1996,1998,2000,2002$ & 2002 & RJs supplementing TBPs \\
\hline 3 & LNK-Chicago O’Hare & $1994,1996,1998,2000,2002$ & 2002 & RJs supplementing MJs \\
\hline 4 & LNK-St. Louis Lambert Int'l & $1994,1996,1998,2000,2002$ & 2002 & RJs replacing MJs \& TBPs \\
\hline 5 & LNK-Kansas City Int'l & $1994,1996,1998,2000$ & N/A & No RJ service \\
\hline 6 & LNK-Omaha Eppley & 1994 & N/A & No RJ service \\
\hline
\end{tabular}
Source: OAG

Examining the situation for each of these routes reveals a variety of cases. For example, in the case of LNK-Denver, the introduction of a capacity cut of 40 percent was accompanied by a doubling of frequency. It appears that RJs' lower breakeven load factor has facilitated more frequent service. The reduction in capacity may well be related to reduced demand post 9/11 so this may suggest that RJs can assist airlines in matching supply with demand. 
The LNK-St. Louis route, by contrast, sees the introduction of five RJ departures to replace four MJ departures and one TBP departure with no change in frequency. This reflects the carriers' strategy to 'right-size' aircraft in an environment of reduced demand and evidence for this route is shown in Figure 10.

Figure 10: LNK-St. Louis Aircraft Types and Route Capacity, 1994-2002
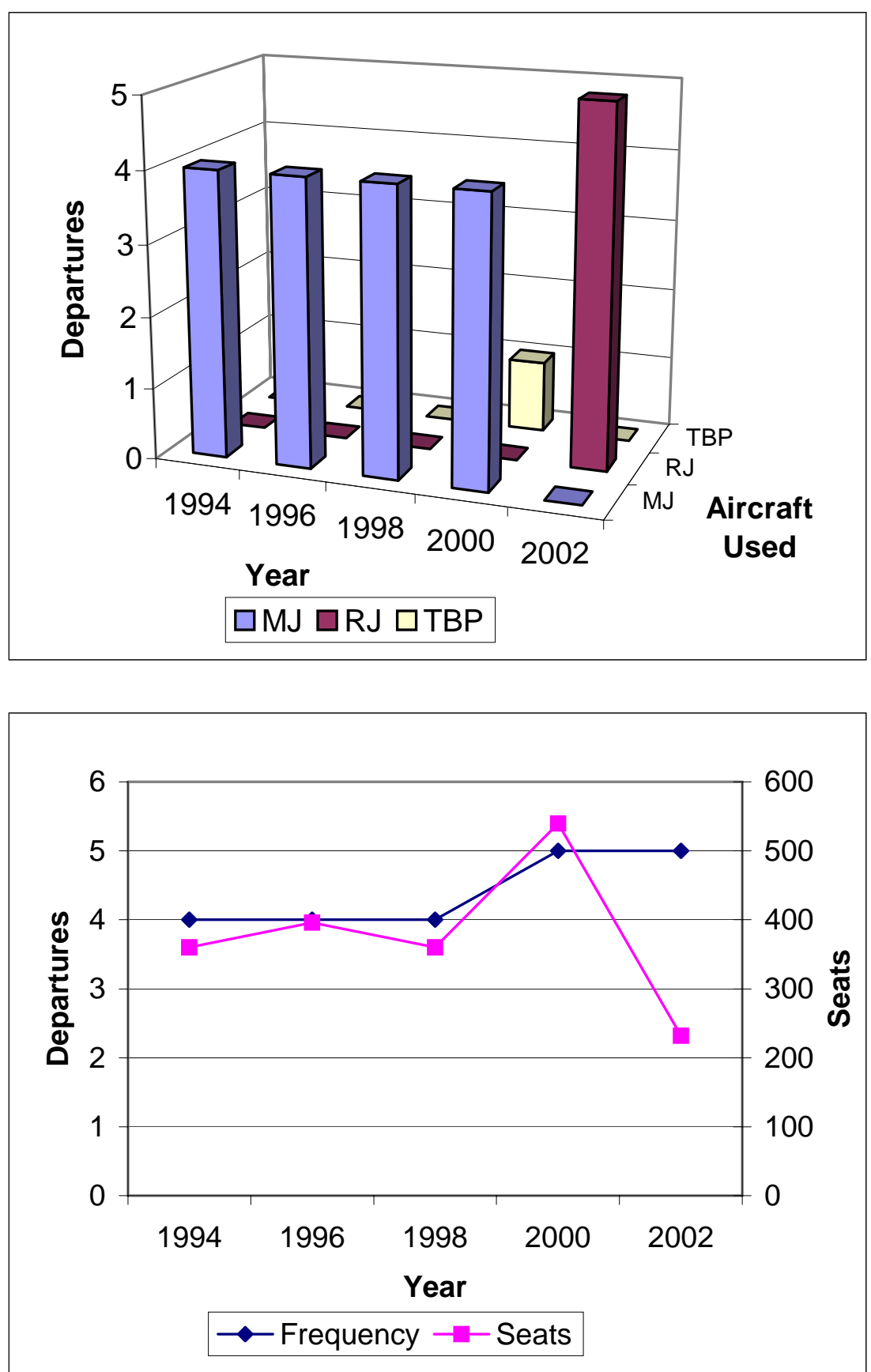

Source: $O A G$ 
In the case of LNK-Minneapolis, the introduction of RJs after 2000 added to the number of seats on offer, so here RJs were used as part of an expansion of capacity strategy. By contrast, LNK-Chicago shows the introduction of RJs as part of a continued effort to reduce capacity, albeit with a halt in the trend of falling frequency.

For SAV-Chicago the service was reinstated with RJs which shows that whereas with MJs the capacity required could not justify sufficient frequency for an attractive and viable service, with RJs, it could.

These highlighted cases show that the impact of RJs varied greatly. Depending on airline strategies and market conditions, RJs affected capacity and frequency levels in diverse ways. The flexibility in RJ usage meant that the introduction of RJs on a certain route had no standard impact. Nevertheless, the analysis has illustrated the spectrum of effects on market dynamics pertaining to the principal RJ deployment strategies.

While the impact on capacity and frequency varied from case to case, none of the routes analysed experienced change in market concentration. Competition between carriers that use RJs, did not occur at SAV or LNK. At least in the small airport context, the use of RJs was not generally associated with airlines entering rival markets. So how did the RJ gain the title of 'saviour of airline competition'?

\subsection{The Case of SAV}

In order to determine whether network competition has indeed increased with the introduction of RJs, the market concentration measures were applied at the airport level. This was only done for SAV as SAV received many new or reinstated routes served exclusively by RJs whereas there were no new routes at LNK. This suggests that network competition may have been enhanced at SAV, depending on which carrier operated the routes. Figure 11 shows the Hirschman-Herfindahl Index, the cumulative number of routes provided exclusively by RJs and the number of effective competitors. 
Figure 11: Market concentration (routes) SAV overall

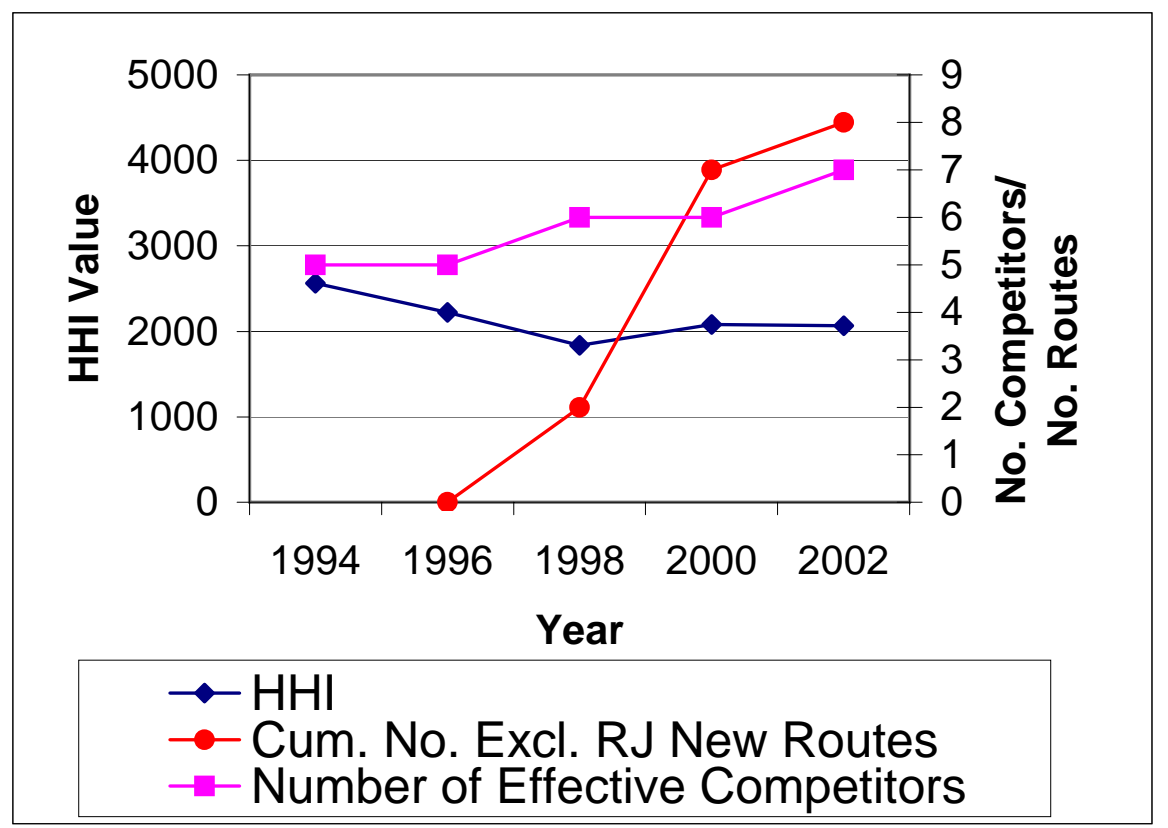

Source: $O A G$

The Figure shows that market concentration has gradually decreased since 1994. This is clearly expressed in the number of effective competitors operating at the airport and, to a lesser extent, the Hirschman-Herfindahl Index. During the same period, numerous new routes attributable to RJs have been launched at the airport. Increased network competition appears to have materialised. Indeed, upon inspecting the schedule data, carriers that have not operated at SAV before were found introducing new routes to the airport using RJs exclusively. Examples include Continental's New York Newark route (1998), Houston Intercontinental route (2000) and Northwest’s Detroit route (2002). Continental and Northwest had no presence at SAV prior to launching these services to their respective hubs. RJ's contribution to enhanced network competition is also highlighted by the stage length of these routes. They were 716, 852 and 711 air miles respectively - well beyond TBP’s range. 
Figure 12: Market concentration (capacity) SAV overall

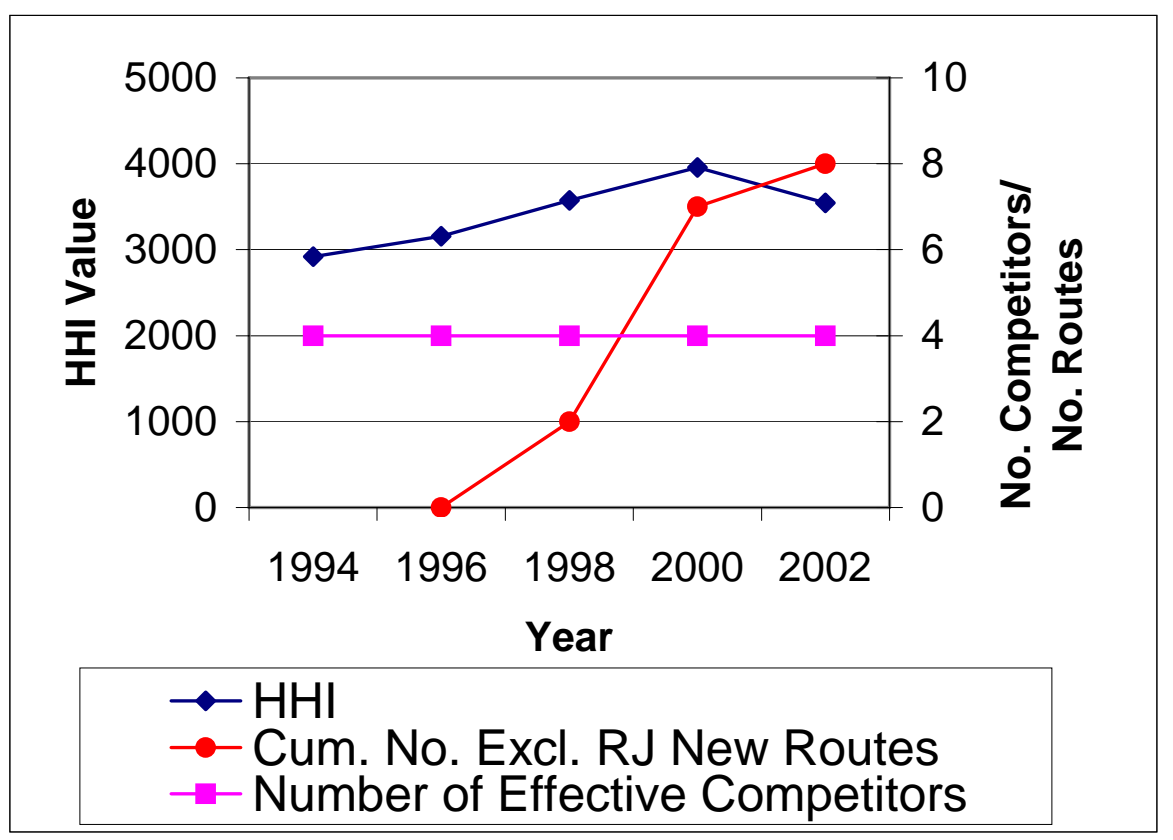

Source: $O A G$

While the fact that RJs facilitated network competition has been confirmed, what was the subsequent improvement in overall market concentration in terms of capacity and the number of departures? The same analysis was therefore applied first to SAV's overall capacity.

Figure 12 shows that even as RJs were used to bring new routes to the airport, market concentration in terms of capacity did not decline. The number of effective competitors remained at four and the HHI value even had an upward trend, signalling increased concentration. This probably has to do with the 'thinness' of the routes introduced by carriers new to SAV. At their peak, Continental and Northwests' shares of capacity at SAV were only 4.11 percent and 3.33 percent respectively.

It is also interesting to note that despite the large number of new routes between 1998 and 2000, the HHI value continued to rise. This suggests that other than new entrants, incumbent airlines at SAV were also using RJs to add new destinations. Closer examination did reveal that during the same period, Delta Airlines, which had the greatest share of capacity, has maintained and even strengthened its position by using RJs to launch new routes too. These include Cincinnati, Dallas/Fort Worth and New York LaGuardia. As from 1998, Delta held more than 50 percent of SAV's seating capacity. Using RJs to add new routes, then, was as much a defensive strategy as an offensive one. 
Figure 13 shows the results for market concentration in terms of service frequency.

Figure 13: Market concentration (departures) SAV overall

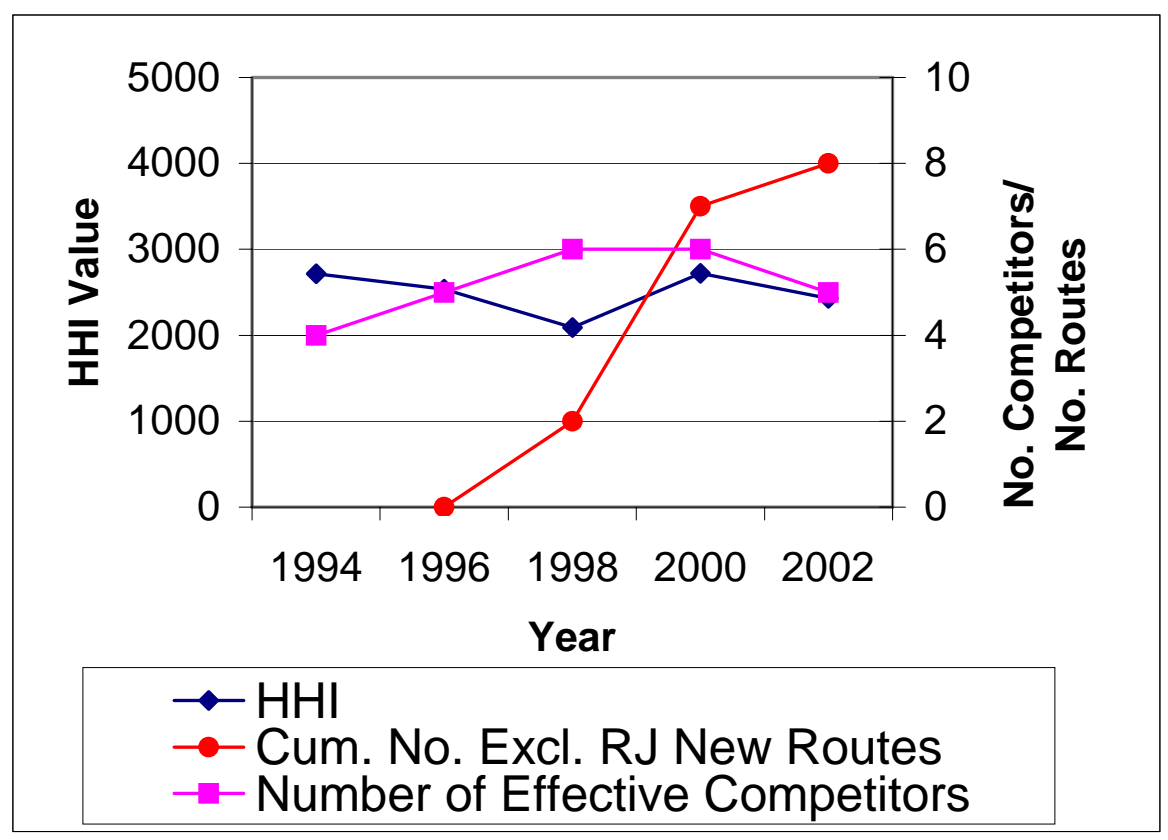

Source: $O A G$

Again, there was no clear improvement in market concentration in terms of departures. Market shares of new entrant Continental and Northwest were low since other airlines also increased the number of flights they operated. This was especially true for Delta, which doubled its departures between 1998 and 2002 from 9 to 18. Closer examination revealed that both Continental and Northwest's shares of departures hovered around 5 percent, which explains the fluctuation in the number of effective competitors. So despite new routes linking the airport to rival hubs, incumbent airlines continued to operate the majority of flights out of SAV.

\subsection{Summary: Impact of RJs on Small Airports}

This section confirms that as airlines have used RJs to enter new markets, airports began to receive service from airlines that did not operate there before. The newcomers at SAV were Continental and Northwest. New routes attributable to RJs have therefore increased passenger choice over airline networks. Market share analysis based on the number of routes each airline operated verified the 
increased network competition. However, further research also showed that new entrants' position at SAV was weak, as incumbents overwhelmingly dominated overall capacity and departures.

This final part of the analysis explored the impact of RJs on individual markets and aimed to deliver a clearer verdict on RJs in the small airport context. The research found that RJs' impact on air service differed greatly even among the two small airports examined. The aircraft played clearly different roles at LNK and SAV.

At LNK, RJs supplemented other aircraft in existing markets. There was an array of effects on capacity and frequency levels, which varied enormously between deployment strategies. At SAV, RJs were used for launching new routes or reinstating discontinued services. For both airports, RJ deployment did not lead to increased carrier competition in individual markets. Probably the most positive impact in terms of competition is that thanks to new routes attributable to RJs, the number of airlines operating out of SAV has increased, thus improving passenger choice over airline networks. However, this was not observed at LNK, where RJ deployment did not translate into new routes.

SAV and LNKs' diverging results showed that it is impossible to ascertain RJs' impact on air service by considering deployment numbers alone. The effects of RJ deployment could vary greatly from route to route, let alone at different airports.

Other literature in this area suggests that since RJs' operating cost for short flights is unfavourable, that there are concerns over small community air service as TBPs give way to all-jet fleets. Continental Airlines has indicated that some smaller markets may lose air service once TBPs are retired (Arnoult, 2002b, DOT, 1998, De Lollis \& Hansen, 2002). New RJ services to nearby medium sized cities may also draw passengers away from small airports, worsening the problem (Vowles, 1999). However, in 1998, the Department of Transport (DOT) found that RJs' negative impact on small communities was 'minimal' (DOT, 1998) but Mesa Airlines described the situation with small markets traditionally served by 19-seat turboprops as ‘ a crisis’ and ‘disastrous’ as late as August 2001 (Marks, 2001). 


\section{Conclusions}

The study aimed to investigate the impact of regional jets from the airport and market perspectives. From case studies of the five sample airports, findings from previous studies were verified and new ones suggested.

The topic was approached from a number of angles. First, the general deployment status of RJs at the sample airports was surveyed. Apart from the general trend of growth, other aspects of RJ deployment varied greatly. Even the pace of growth differed. While deployment accelerated at CVG, PHX and LNK after 9/11, it slowed at LGA and SAV. It was found that isolating routes served exclusively by RJs for analysis yielded interesting results. While CVG seemed most RJ-intensive in terms of the number of routes involving RJs, SAV stood out as most RJ-reliant in terms of routes flown only by the aircraft. Further analysis confirmed the GAO’s findings that RJs have been used to add spokes to hubs GAO (2001). All RJ routes from small airports were destined for large hubs while RJ services from large airports mostly went to small/medium hubs.

The second part of the analysis assessed the impact of RJs at the airport level, specifically in terms of whether RJs have facilitated the development of new markets. Both CVG and SAV received many new routes attributable to RJs. While the former received the highest number of new routes, it was the latter that saw the most dramatic percentage rise in the total number of routes operated as a result. As the study found RJs playing an increasingly important role in new market development at certain airports, it also foresaw a potential danger of over-reliance on RJs for that purpose. Since RJs are only suited for certain market types, the diversity of destinations may be jeopardised if just RJs were used for developing new routes. On the other hand, RJs had only limited impact at LGA and PHX regarding new markets. RJs did not facilitate any new routes at LNK. The GAO's finding of RJs being used on new routes in 41 percent of cases could therefore be misleading. In terms of the new destinations' size, all new routes from SAV were to large hubs. The larger airports had more varied new destinations and more importantly, different from existing RJ routes. The study also made findings on the length of new routes facilitated by RJs. They often lay between the operating range of TBPs and MJs. From the combination of results, it appears that, at least at certain airports, RJs' particular performance capabilities and economics have indeed opened new markets that were unviable 
before. Analysis also discovered that new routes attributable to RJs were rarely subsequently discontinued.

In the final part of the analysis, RJs' effects on individual markets and carrier competition were examined in the small airport context. The impact of RJs' on markets dynamics was found to be as varied as the different RJ deployment categories. As RJs were flexibly used to replace or supplement other aircraft types, a spectrum of effects on route capacity and frequency could be observed. While RJs were championed as 'saviour[s] of airline competition' (MITRE, 2000), the study found that the introduction of RJs did not alter the level of market concentration at the individual route level at either LNK or SAV. However, RJs did enhance network competition at SAV. But as incumbents also capitalised on opportunities offered by RJs, the overall market share of new entrants remained insignificant. The analysis also investigated industry concerns that RJs would spell the end to many TBP routes. Some evidence of this was found at both LNK and SAV but the study could not be conclusive. Lastly, even as LNK and SAVs' experiences with RJs were fundamentally different, personal interviews with senior airport staff revealed that both airports viewed RJs very positively.

This paper has revealed that numerous deployment strategies were employed. RJs were used on their own as well as for supplementing or replacing other equipment. They were instruments for launching new routes, increasing frequency while maintaining capacity and vice versa. RJs’ versatility translated into a spectrum of effects on air service, some more prominent than others at any given airport.

Even if airlines’ enthusiasm over RJs’ original and unique capabilities are justified, airports should not be too swift to share the excitement. Although some airports, such as Savannah, have undoubtedly reaped benefits from the advent of RJs, others - and perhaps the majority - have seen little impact. In the brouhaha over RJs' seemingly omnipotence in improving air service at small communities, Lincoln's case proved revealing. Indeed, service frequency has increased but at the expense of capacity. Basic economics (e.g. low demand) and the very nature of the airport (e.g. location) continued to inhibit new routes, in spite of RJs. Their invention has not altered the fundamental requirements for viable operation. 
While acknowledging that the regional jet has made a significant mark on U.S. air transport over the last decade, its limitations as well as abilities should be recognised. As the hype over RJs continues, it is worthwhile realising that, so far, the 'revolution' has only come to particular airports, certainly not all and the aggregate picture described by the industry and government is in fact a combination of highly dissimilar cases. This could be more firmly established with a greater number of case study airports. 


\section{REFERENCES}

ACI, 2002, North American Airports Traffic Statistics. Airports Council International - North America. Washington, D.C. (http://www.aci-na.org/docs/Pax.htm accessed 10/04/03)

Air Transport World, 2002. US Airways forms RJ subsidiary. Air Transport World. 39 (7) July. 22.

Aircraft Commerce, 2002. US regional airline development \& fleet plans. Aircraft Commerce. No. 22, April/May. 37 - 42.

Arnoult, S., 2002a. The shakeout arrives. Air Transport World. May. 30 - 32.

Arnoult, S., 2002b. ExpressJet stretches to grow. Air Transport World. November. 51 - 55.

Belobaba, P., Van Acker, J., 1994. Airline market concentration. Journal of Air Transport Management 1(1) $5-14$.

Bernstein, G., Abbey, D., 1997. The Regional jet frenzy. STG Reports. Stanford Transportation Group. October. (http://www.stg-llc.com/Pages/stgrpts.htm accessed 18/07/02)

Croft, J., 2002. ATC: Regional Jets Vexing But Manageable. Aviation Week \& Space Technology 156 (19), 47.

De Lollis, B., Hansen, H., 2002. Airlines abandon small cities. USA Today. October 23rd.

Delta Airlines, 2002. Delta Connection A Special Report. August.

Dresner, M., Windle, R., Zhou, M., 2002. Regional jet services: supply and demand. Journal of Air Transport Management 8, $267-273$.

DOT, 1998. Profile: Regional jets and their emerging roles in the U.S. aviation market. Office of the assistant secretary for aviation and international affairs. Department of Transportation. June. Washington, D.C.

FAA, 1997. Proceedings of the $22^{\text {nd }}$ Annual FAA Commercial Aviation Forecast Conference. Federal Aviation Administration. March. Washington, D.C.

Fiorino, F., 2002.What A Difference A Decade Makes: Regionals Rise Above Adversity. Aviation Week \& Space Technology. July $22^{\text {nd }} .136-141$.

GAO, 2001. Regional Jet Service Yet to Reach Many Small Communities. General Accounting Office. February. Washington, D.C. 
Goold, I., 2001. RJX tests accelerate as jet No. 2 joins program. Aviation International News. September. (www.ainonline.com/issues/09_01/09_01rjxtestpg100.html accessed 30/05/02)

Graham, B., 1997. Regional airline services in the liberalized European Union single aviation market. Journal of Air Transport Management 3 (4), 227 - 238.

Higgins, A., 2001. Regional carriers vital to air travel. The Cincinnati Enquirer. March $27^{\text {th. }}$

Jaworowski, R., 2000. New regional aircraft market study released. Journal of Aerospace and Defense Industry News. September $26^{\text {th }}$.

Marks, A., 2001. Future of air travel: regional service, but in smaller jets. The Christian Science Monitor. August 21st.

MITRE, 2000. Regional Jets. The MITRE Corporation. (www.mitre.org accessed 28/05/02)

MITRE,2002. MITRE Annual Report at

(http://www.mitre.org/about/annual_reports/annual_02/index.html accessed 20/02/04)

Morrison, S., Winston, C., 1995. The evolution of the airline industry. Brookings Institute. Washington, D.C.

Pagiola, S., 2002. American Eagle’s Regional Jets. Airways. April. 21 - 27.

RAA, 2001. Annual Report 2001. Regional Airline Association. Washington, D.C.

RAA, 2002. Annual Report 2002. Regional Airline Association. Washington, D.C.

RASI, 2003. Regional Air Service Initiative website. (www.regionalairservice.org accessed 18/04/03)

Razzhivina, 2001. Shake-out looms for RJ-builders. The Avmark Aviation Economist. September. 19 21.

Sobie, B., 2002. Making the connection. Flight International. October $1^{\text {st }}-7^{\text {th }} .46-49$.

Vowles, T., 1999. Predicting the loss of commuter air service in the Untied States. Journal of Air Transport Management 5, $13-20$. 
Appendix A RJ models considered in the study

Avro Int'l Aerospace Avroliner RJ 70 Avro Int'l Aerospace Avroliner RJ 85

Avro Int'l Aerospace Avroliner RJ 100

Avro Int'l Aerospace Avroliner RJ 115

Canadair Regional Jet 100

Canadair Regional Jet 200

Canadair Regional Jet 700

Canadair Regional Jet 900

Embraer RJ 135

Embraer RJ 140

Embraer RJ 145

Fairchild Dornier 328Jet

Fairchild Dornier 728Jet 


\section{Appendix B Aircraft observed in the study and their typical seating capacities}

\begin{tabular}{|c|c|}
\hline \multicolumn{2}{|l|}{ Mainline Jets } \\
\hline Model & Typical seating capacity \\
\hline Boeing 757 - All Series & 222 \\
\hline Boeing 737-500 & 110 \\
\hline Boeing 737-300 & 126 \\
\hline Boeing 737 Advanced All Series & 153 \\
\hline Boeing 737-800 & 172 \\
\hline Boeing 737-400 & 147 \\
\hline Boeing 727 Advanced - All Series & 150 \\
\hline Boeing 717 & 106 \\
\hline Airbus A318/319/320/321 & 142 \\
\hline Airbus A320-100/200 & 150 \\
\hline Airbus A319 & 124 \\
\hline McDonnell Douglas DC9 10/20 Series & 90 \\
\hline McDonnell Douglas DC9 30/40/50 Series & 120 \\
\hline McDonnell Douglas MD-80 All Series & 144 \\
\hline Fokker 100 & 107 \\
\hline British Aerospace 146 All Series ${ }^{5}$ & 96 \\
\hline Fokker F28 Fellowship All Series & 85 \\
\hline \multicolumn{2}{|l|}{ Sources: OAG, manufacturers, RAA. } \\
\hline \multicolumn{2}{|l|}{ Regional Jets } \\
\hline Model & Typical seating capacity \\
\hline Avro Intl Aerospace Avroliner & 85 \\
\hline Avro Intl Aerospace Avroliner RJ100/115 & 108 \\
\hline Avro Intl Aerospace Avroliner RJ70 & 70 \\
\hline Avro Intl Aerospace Avroliner RJ85 & 85 \\
\hline Canadair Regional Jet & 50 \\
\hline Canadair Regional Jet 100/200 & 50 \\
\hline Canadair Regional Jet 700 & 70 \\
\hline Canadair Regional Jet 900 & 86 \\
\hline Embraer RJ 135/140/145 & 44 \\
\hline Embraer RJ 135 & 37 \\
\hline Embraer RJ 135/145 & 44 \\
\hline Embraer RJ 140 & 44 \\
\hline Embraer RJ 145 & 50 \\
\hline Fairchild Dornier 328Jet & 33 \\
\hline Fairchild 728Jet & 75 \\
\hline
\end{tabular}

Sources: OAG, manufacturers, RAA.

\section{Turboprops}

Model

Fairchild Dornier 328

Fairchild Metroliner

Typical seating capacity

19

British Aerospace Jetstream 41

British Aerospace Jetstream $31 \quad 19$

Embraer EMB-120 Brasilia $\quad 30$

Beechcraft All Series 17

de Havilland DHC8 Dash-8 All Series $\quad 51$

de Havilland DHC8 Dash-8 Series $300 \quad 52$

Saab SF 340

Aerospatiale/Alenia All Series 59

Aerospatiale/Alenia ATR72 72

Sources: OAG, manufacturers, RAA.

${ }^{5}$ Older aircraft such as the British Aerospace 146 are excluded from the RJ category due to reasons explained in the body of the paper. These older small jets are classified as MJs for the purpose of this paper. 